\title{
Kolcaba'nın Konfor Kuramına Göre Atriyal Fibrilasyon Olgusu
}

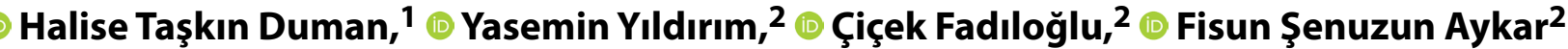 \\ ${ }^{1}$ Muğla Sıtkı Koçman Üniversitesi Fethiye Sağlık Bilimleri Fakültesi, İç Hastalıkları Hemşireliği Anabilim Dalı, Muğla \\ 2Ege Üniversitesi Hemşirelik Fakültesi, İç Hastalıkları Hemşireliği Anabilim Dalı, İzmir
}

\begin{abstract}
Özet
Hemşirelikte kavramsal modellerin kullanımı hemşirelik bakımına eleştirel bir bakış açısı, bilimsel temel kavram ve prensipler kazandırarak hasta bireyde etkin bir bakım oluşturur. Hemşirelik bakımında kullanılan kavramsal modellerden biride Katharine Kolcaba tarafından geliştirilen 'Konfor Kuramı'dır. Kuramda holistik görüşle konfor kavramını, ferahlama, rahata kavuşma ve sorunların üstesinden gelebilmek için temel insan gereksinimlerini karşılamanın o andaki deneyimi olarak açıklamaktadır. Bu olguda atriyal fibrilasyon tanısı nedeniyle kardiyoversiyon ve ablasyon uygulanan bir hastanın konfor kuramına göre hemşirelik bakım süreci gerçekleştirilmiştir.
\end{abstract}

Anahtar sözcükler: Atriyal fibrilasyon; konfor kuramı; olgu sunumu.

\section{A Case of Atrial Fibrillation According to Kolcaba's Comfort Theory}

\begin{abstract}
The use of conceptual models in nursing creates a critical point of view of nursing care, scientific basic concepts and principles and provides effective care for the sick individual. One of the conceptual models used in nursing care is 'Theory of Comfort' developed by Katharine Kolcaba. In theory he describes the concept of comfort with holistic view as the current experience of relieving, resting and meeting basic human needs to overcome problems. In this case, the nursing care process was performed according to the comfort theory of a patient who underwent cardioversion and ablation for atrial fibrillation. Keywords: Atrial fibrillation; case report; theory of comfort.
\end{abstract}

Cite this article as: Taşkın Duman H, Yıldırım Y, Fadıloğlu Ç, Şenuzun Aykar F. A Case of Atrial Fibrillation According to Kolcaba's Comfort Theory. Turk J Cardiovasc Nurs 2020;11(24):37-42.

$\mathrm{H}$ emşirelik mesleğinin birincil işlevi günlük yaşam aktivitelerini ve temel insan gereksinimlerini yerine getiremeyen bireylerin bakımına destek olarak yaşamlarını en iyi şekilde sürdürmelerini sağlamaktır. Gerçekleştirilen hemşirelik bakımı ile bireyin yaşamı daha konforlu hale gelerek yaşam kalitesi artmaktadır. Hemşirelik mesleğinde yapılan bakım ve uygulamalar hemşire kuramcılar tarafından geliş- tirilen kavram ve kuramlar çerçevesinde yürütülmektedir. Kolcaba'nın Konfor Kuramı; kuramsal, çok boyutlu ve holistik olarak tanımlanabilir. Holistik görüşe göre konfor kavramı; huzura kavuşma, ferahlama ve sorunları çözmek için temel insan gereksinimlerini karşılamadır. ${ }^{[1]}$ Hemşireler, hastaların konforunu bozan etkenleri tespit edip ortadan kaldırarak hastaların güçlenmesine ve yenilenmesine yar-

İletişim (Correspondence): Halise Taşkın Duman. Muğla Sıtkı Koçman Üniversitesi Fethiye Sağlık Bilimleri Fakültesi,

iç Hastalıkları Hemşireliği Anabilim Dalı, Muğla, Turkey

Telefon (Phone): +90 5053123954 E-Posta (E-mail): halisetaskinduman@gmail.com

Başvuru Tarihi (Submitted Date): 18.10.2019 Kabul Tarihi (Accepted Date): 20.04.2020

CCopyright 2020 by Turkish Society of Cardiology - Available online at www.anatoljcardiol.com

OPEN ACCESS This work is licensed under a Creative Commons Attribution-NonCommercial 4.0 International License. 
dımcı olurlar. ${ }^{[2]}$ Hemşirelikte konfor, kaliteli bakımın temeli olarak kabul edilir. Kolcaba, hemșirelik bakım sürecinde bireylerin konfor ihtiyaçlarının karşılanmasında rehber olarak konfor kuramından yararlanılabileceğini belirtmiştir. ${ }^{[3,4]}$

\section{Konfor Kuramı}

Kolcaba holistik görüşle konfor kavramını, rahata kavuşmak, ferahlamak ve sorunları çözebilmek için temel insan gereksinimlerini karşılamanın o andaki deneyimi olarak açıklamaktadır. Kurama göre hemşire; hasta ve aile üyelerinin rahatlık ihtiyaçlarını belirler ve bu ihtiyaçları karşılamak için girişimlerini tasarlar ve uygular. Kolcaba'ya göre konfor; 'Üç tür konfor boyutunun herhangi biri için ihtiyaçların karşılanması ile güçlenmenin deneyimidir' ${ }^{[3]}$

Kolcaba, kuramın taksonomik yapısını konfor düzeyleri ve konfor boyutları olarak iki aşamada incelemiştir (Tablo 1). ${ }^{[2]}$

\section{Birinci Aşama}

Ferahlama: Bireyin gereksinimlerinin karşılanmasıyla birlikte sıkıntıdan kurtulması ile hissettiği duygudur. Huzurlu ölüm ya da eski fonksiyonlarına dönmek için gereklidir. ${ }^{[5,6]}$

Rahatlama: Rahat, sakin ve huzur içinde olma durumu olarak tanımlanmıştır. Bireyin rahatlaması, memnun olduğunu belirtmesi durumudur. ${ }^{[2]}$

Üstünlük: Bireyin sorunlarının çözülmesi ve gücünün artırılması olarak tanımlanmaktadır. Konfor; hastanın kendini kontrol etme ve planlamada özgür olmasını amaçlar. Konfor ihtiyaçları tam olarak karşılanan birey, sorunların üstesinden gelme düzeyine ulaşabilmektedir. ${ }^{[2,4]}$ Üstesinden gelmeyi diğer iki kavramdan ayıran, bireyin sıra dışı performans potansiyelini ortaya çıkarmasıdır. Her üç konfor düzeyi, hastanın performansını olumlu yönde etkileyen güç verici bileşenlerdir. ${ }^{[7]}$

Bu üç gereksinim alanında konforu karşılanmayan birey eksiklik hisseder. ${ }^{[1,2]}$

\section{İkinci Aşama}

Fiziksel konfor: Bireyin fiziksel durumunu etkileyen din- lenme ve gevşeme, hastalığa karşı verdiği yanıtlar, beslenme, homeostazis, barsak fonksiyonunun devamlılığı gibi fizyolojik faktörleri içermektedir. Ağrı, fiziksel konforun azalmasında en büyük etkenlerden biridir. Fizyolojik göstergelerin birinde var olan normalden sapma konforu etkilemektedir. ${ }^{[6,7]}$

Psiko-spiritüel konfor: Mental, emosyonel ve manevi bileşenlerden oluşmaktadır. Öz-saygı, benlik kavramı, cinsellik ve kendinin farkında olma gibi duygular bireyin yaşamına anlam veren öğeleri kapsamaktadır. ${ }^{[7,8]}$

Çevresel konfor: Çevresel konfor dış etkenler ve bunların insan üzerindeki etkilerini kapsamaktadır. Aydınlık, gürültü, renk, sıcaklık, güvenilir çevre gibi insanın dış ortamı ile ilgili kavramlar bu kapsamda yer almaktadır. ${ }^{[3,6]}$

Sosyo-kültürel konfor: Kolcaba'ya göre hemşireler, sosyal konforu destekleyebilirler. Sosyo-kültürel bakımı oluşturan etkenler arasında;ailenin sosyokültürel ve dini inançları doğrultusunda bilgi ve danışmanlık yapılması, bakım verme, finansal destek sistemlerinden yararlanma, kişilerarası iletişimin sağlanması, taburculuk eğitimi ve evde bakımın sağlanması yer almaktadır. Sosyo-kültürel konforu azaltan etkenler, kültürel geleneklerin önemsenmemesi, aileden ayrılma, bakımın sürekli olmaması, bakım kalitesinin kötü olması gibi faktörlerdir. Hemşireler, sağlık ekibinin diğer üyeleri ve hastanın ailesi duyarlı davranarak sosyal konforu kolaylaştırabilirler. ${ }^{[9,10]}$ Güvensizlik, konforu azaltan bir diğer faktördür. Hastane donanımının iyi olmaması, güvenlik tedbirlerinin az olması, aseptik tekniğin doğru uygulanmaması, nozokomiyal infeksiyonlar güvensizliği arttıran faktörlerdir. ${ }^{[11,12]}$

Kolcaba; konforun kavramsal çalışmalarını tamamladıktan sonra taksonomik yapıyı test etmek ve hastada beklenen konfor sonucunu ölçmek için 48 maddeden oluşan, altılı likert tipte Genel Konfor Ölçeği (GKÖ)'ni geliştirmiştir. Ülkemizde Kuğuoğlu ve Karabacak erişkin hastalarda 'Genel Konfor Ölçeğinin Türkçeye Uyarlanması' çalışmasını gerçekleştirerek ölçeğin Türkçe formunun genel konforu değerlendirmede geçerli ve güvenilir olduğu sonucuna varmışlardır. ${ }^{[13]}$

\begin{tabular}{|c|c|c|c|}
\hline \multirow[t]{2}{*}{ Konfor Kuramı } & \multicolumn{3}{|c|}{ Boyutları } \\
\hline & Ferahlama & Huzur/Rahatlama & Anlam Bulma/Üstünlük \\
\hline \multicolumn{4}{|l|}{ Düzeyleri } \\
\hline \multicolumn{4}{|l|}{ Fiziksel } \\
\hline \multicolumn{4}{|l|}{ Psikospiritüel } \\
\hline \multicolumn{4}{|l|}{ Çevresel } \\
\hline Sosyokültürel & & & \\
\hline
\end{tabular}


Sonuç olarak, bireyin fiziksel, psiko-spiritüel, çevresel ve sosyo-kültürel değerlendirilmesi yapılarak; ferahlama, huzur, anlam bulma sorunlarının tespiti gerçekleştirilir. Sonraki süreçte uygun hemşirelik girişimleri uygulanarak bu sorunlar çözümlenir ve kişinin konforu sağlanmış olur.

\section{Olgu Sunumu}

Yaklaşık 20 yıldır diabetes mellitus (DM) ve hipertansiyonu olan 72 yaşındaki bayan F. Ö'ye üç hafta önce atriyal fibrilasyon (AF) tanısı ile kardiyoversiyon uygulanmış ve normal sinüs ritmi ile taburcu edilmiştir. Ancak üç gün önce kalbinde sıkışma, çarpıntı şikayeti ile kardiyoloji polikliniğe yeniden başvuran hastanın yapılan muayenesinde AF'nin tekrarladığı tespit edilmiş ve hastaya ablasyon yapılması amacıyla kardiyoloji servisine yatışı yapılmıştır. Hastaya iki gün önce ablasyon girişimi uygulanmış ve sonrasında bir gece kardiyoloji yoğun bakım ünitesinde izlemi yapılmıştır. Normal sinüs ritmi sağlanan ve komplikasyon gelişmeyen hastanın kardiyoloji servisine transferi gerçekleştirilmiştir. Ancak hastanın serviste yapılan takiplerinde ritminin tekrar AF'ye döndüğü tespit edilmiş ve hastaya tekrar kardiyoversiyon uygulanılmasına karar verilmiştir. Hasta farmakolojik tedavi olarak Kalsiyum Kanal Blokörü (Diltizem 90 mg SR), Sitagliptin/Metformin (Janumed 50/1000 mg tb 1x1), Gliklazid (Betanorm $30 \mathrm{mg}$ tb 1x1), İrbesartan ve Hidroklorotiyazid (Arbesta plus 300/125 mg tb 1x1), Amiodaron Hidroklorür (Cordarone 200 mg tb 1x1), ve Varfarin Sodyum (Coumadin $10 \mathrm{mg}$ tb1x1) kullanmaktadır.

Hastanın yapılan fiziksel değerlendirmesinde; yaşam bulguları; vücut sıcaklığı 36.50C, nabız 148/dk (distritmi mevcut), kan basıncı 110/70 mmHg, solunum $26 / \mathrm{dk}$, oksijen satürasyonu $\% 90$ 'dır.

Hastanın boyu $1.54 \mathrm{~cm}$, kilosu $92 \mathrm{~kg}$ olup Beden Kitle İndeksi (BKI) $38.8 \mathrm{~kg} / \mathrm{m}^{2}$ dir.

Laboratuvar bulguları; Eritrosit 3.99 milyon/ $\mu \mathrm{L}$, Hemoglobin 11.2 g/L, INR 1.35, açlık kan şekeri 207 mg/dl dir. Hastanın kardiyak enzimleri normal bulunmuştur. Hastanın ödemi yok ancak cildi kuru ve girişim uygulanan sol femoral bölgede ağrı ve hematom tespit edilmiştir. Hastanın kalp hızının kontrol altına alınması için Elektrokardiyografi (EKG) kontrolünde beta bloker olan Beloc $50 \mathrm{mg}$ ampul IV puşe olarak yapılmış ve kontrol EKG'sinde ritim hızı 112/dk'ya düştüğü tespit edilmiştir. Hastanın ritmi monitörize edilip hızı açısından yakın takibe alınmıştır. Ayrıca satürasyon düzeyinin düşük olması nedeniyle hastaya $3 /$ lt den nazal kanülle oksijen tedavisi başlanmıştır.

Toplanan veriler doğrultusunda olgunun konfor kuramının düzey ve boyutlarına göre hemşirelik tanı ve girişimleri be- lirlenmiştir (Tablo 2).

Konfor Kuramına Göre Fiziksel Olarak;

- F. Ö kasık bölgesinde ağrı olduğunu, yürürken zorlandığını ifade etti. Hastanın mimiklerinde ağı ifadesi gözlendi. Ağrı şiddeti görsel analog ölçeği (vizüel analog scale-VAS) ile değerlendirildi. Hasta ağrısının şiddetini 4 olarak değerlendirdi.

Hemşirelik tanısı 1: Ağrı (NANDA Alanı 12: Konfor, Sınıf 1: Fiziksel konfor) ${ }^{[14]}$

Beklenen sonuç: Hastanın ağrısının giderilmesi/azaltılması.

Hemşirelik girişimleri: Ağrının şiddeti takip edildi. Kasık üzerine soğuk uygulama yapıldı. Kasığını koruyacak şekilde pozisyon verildi. Dikkatini başka yöne çekmek için televizyon izlemesi sağlandı. Hekim istemi ile analjezik uygulandı.

Değerlendirme: Hastanın ağrısı VAS ile değerlendirildiğinde ağrı şiddeti "1" olarak ölçüldü.

- Hasta çarpıntısının olduğunu ifade etti. Yaşam bulguları kontrol edildi. Oksijen satürasyonu $\% 90$, solunum sayısı 26/dk, nabız sayısı 148/dk tespit edildi.

Hemşirelik tanısı 2: Kardiyak doku perfüzyonunda azalma riski (NANDA Alanı 4: Aktivite/Dinlenme, Sınıf 4: Kardiyovasküler/Pulmoner yanıt). ${ }^{[14]}$

Beklenen sonuç: Kardiyak doku perfüzyon sürekliliğinin sağlanması.

Hemşirelik girişimleri: Hastanın ritmi monitörize edildi. Hekim istemi ile betabloker grubu ilaç ve oksijen tedavisi $3 \mathrm{lt} / \mathrm{dk}$ uygulandı. Hareketleri sınırlandırıldı. Yatak içinde pasif hareketlere izin verildi. Ağır ve fazla yemek yemesi önlendi. Sık ve az yemek yemesi sağlandı.

Değerlendirme: Kontrol EKG'sinde nabzının 112/dk olduğu, oksijen satürasyonunun \%96'ya yükseldiği tespit edilmiş olup hasta çarpıntı hissinin azaldığını ifade etti.

- F. Ö'nün ablasyon işlemi sonrası sol kasık bölgesinde hematom tespit edildi. Hastanın varfarin grubu ilaç kullanıyor olması.

Hemşirelik tanısı 3: Kanama riski (NANDA Alanı 11: Güvenlik/ Korunma, Sınıf 2: Fiziksel yaralanma) ${ }^{[14]}$

Beklenen sonuç: Oluşmuş hematomun küçülmesi ve kanamanın önlenmesi

Hemşirelik girişimleri: Hematom büyüklük açısından takip edildi. Kasık üzerine soğuk uygulama yapıldı. Hematom altında kalan ekstremitelerde nabız dolgunluğu, deri ısısı ve rengi izlendi. Laboratuvar bulguları (eritrosit, hemoglobin, INR) takip edildi. Kanama belirtileri (melena, hematüri, ekimoz, peteşi v.b) takip edildi.

Değerlendirme: Hematomda büyüme tespit edilmedi. F. 


\begin{tabular}{|c|c|c|c|}
\hline Konfor Kuramı Düzeyleri & Ferahlama & Huzur/Rahatlama & Anlam Bulma/Üstünlük \\
\hline \multicolumn{4}{|l|}{ Fiziksel } \\
\hline o Ağrı & $\begin{array}{l}\text { Non-farmakolojik ve farmakolojik } \\
\text { girişimlerin uygulanması }\end{array}$ & $\begin{array}{l}\text { Hastanın ağrısının giderilerek/ } \\
\text { azaltılarak rahatlatılması }\end{array}$ & Ağrı ile başetmenin sağlanması \\
\hline azalma riski & Farmakolojik müdahalelerin yapılması & getirerek rahatlatılması & \\
\hline o Kanama riski & $\begin{array}{l}\text { Non-farmakolojik ve farmakolojik } \\
\text { girişimlerin uygulanması } \\
\text { Kanama bulgularının takip edilmesi }\end{array}$ & $\begin{array}{l}\text { Hematomun küçülmesinin } \\
\text { sağlanarak hastanın } \\
\text { rahatlatılması }\end{array}$ & Kanamanın önlenmesi \\
\hline \multicolumn{4}{|l|}{ Psiko-spiritüel } \\
\hline \multicolumn{4}{|l|}{ Çevresel } \\
\hline $\begin{array}{l}\text { o Uyku örüntüsünde } \\
\text { Bozulma }\end{array}$ & $\begin{array}{c}\text { Görsel ve sesli uyaranların azaltılarak } \\
\text { uyumasının sağlanması }\end{array}$ & $\begin{array}{l}\text { Uyku örüntüsünün düzelmesi } \\
\text { sağlanarak hastanın rahatlaması }\end{array}$ & $\begin{array}{c}\text { Uyku örüntüsünün } \\
\text { devamlılığının sağlanması }\end{array}$ \\
\hline o Korku & Korkularını ifade etmesinin sağlanması & $\begin{array}{l}\text { Korkularının giderilerek } \\
\text { rahatlamasının sağlanması }\end{array}$ & $\begin{array}{l}\text { Korkularının üstesinden } \\
\text { gelmesinin sağlanması }\end{array}$ \\
\hline o Konforda bozulma & $\begin{array}{c}\text { Girişimlerin konforu en az etkileyecek } \\
\text { şekilde uygulanması }\end{array}$ & $\begin{array}{l}\text { Girişimlerin günlük yaşam } \\
\text { aktivitelerini etkilemeyecek } \\
\text { şekilde uygulanması }\end{array}$ & $\begin{array}{c}\text { Günlük yaşam aktivitelerinin hasta } \\
\text { tarafından devam ettirilmesinin } \\
\text { sağlanması }\end{array}$ \\
\hline o Düşme riski & $\begin{array}{l}\text { Çevrenin düşmeyi önleyecek şekilde } \\
\text { düzenlenmesi, hasta ve yakınlarının } \\
\text { bilgilendirilmesi }\end{array}$ & $\begin{array}{c}\text { Düşmenin önlenerek konforun } \\
\text { devam ettirilmesi }\end{array}$ & $\begin{array}{l}\text { Vücut bütünlüğünün } \\
\text { devamlılığının sağlanması }\end{array}$ \\
\hline \multicolumn{4}{|l|}{ Sosyo-kültürel } \\
\hline $\begin{array}{l}\text { o Risk eğilimli sağlık } \\
\text { davranışı }\end{array}$ & $\begin{array}{l}\text { Bilgi eksikliğini giderilmesi ve } \\
\text { diyetisten ile işbirliği yapılması }\end{array}$ & $\begin{array}{c}\text { Beslenmesinin hastalığına } \\
\text { uygun yapılması }\end{array}$ & $\begin{array}{l}\text { Diyetine uyum sağlayarak } \\
\text { beslenmenin sürdürmesi }\end{array}$ \\
\hline
\end{tabular}

Ö'nün vücudunda kanama bulgusuna rastlanmadı.

Konfor Kuramına Göre Psiko-spiritüel Olarak;

- F.Ö. çarpıntısının devam edeceği korkusunun olduğunu, kendisine yapılan girişimlerin ne kadar tekrarlanacağını, düzelme olmazsa ne yapacağını, bu şekilde rahat yaşayamayacağını belirtti.

Hemşirelik tanısı 4: Anksiyete (NANDA Alanı 9: Başetme/ Stres toleransı, Sınıf 2: Başetme) ${ }^{[14]}$

Beklenen sonuç: Anksiyete ile başetmenin sağlanması

Hemşirelik girişimleri: Hastanın kendini ifade etmesi sağlandı. Hastada stres ve anksiyeteye neden olan korkularını açıklamasına olanak verildi. Hasta özellikle işlem sonrası yoğun bakım sürecinde kendisini yalnız ve ölecekmiş gibi hissettiğini bildirdi. F. Ö. normalde çok hareketli olduğunu her işini kendisinin yaptığını ama son bir aydır başkalarına bağımlı olduğunu bu yüzden kendisini rahatsız hissettiğini belirtti. Bunun üzerine hastanın hekimi ile iletişime geçilerek vizit saatinde ailesi ile birlikte hastanın kaygıları hakkında konuşma ortamı sağlandı. Hastaya hastalık sürecinde neler yaşayabileceği, ritim probleminin çözümleneceği, bunun için süreç gerektiği, bu sürecin sonunda normal aktivitelerine dönebileceği anlatıldı.

Değerlendirme: Hastanın anksiyetesi devam ediyor.

Konfor Kuramına Göre Çevresel Olarak; 
- F. Ö. uykusunun hassas olduğunu, hastanedeki ışık ve gürültü nedeniyle uyuyamadığını, çok sık uykusunun bölündüğünü bu nedenle yorgun olduğunu bildirdi.

Hemşirelik tanısı 5: Uyku örüntüsünde bozulma (NANDA Alanı 4: Aktivite/Egzersiz, Sınıf 1: Uyku/Dinlenme) $)^{[14,15]}$

Beklenen sonuç: Hastanın yeterli uyumasının ve dinlenmesinin sağlanması.

Hemşirelik girişimleri: Hasta tek kişilik odaya alındı. Monitör uyarı aralıkları hastanın tıbbi tanı ve yaşına göre ayarlandı. Ziyaretçi kısıtlaması yapıldı. Gündüz uyuması azaltıldı. Hastanın odasındaki ışık ve sesli uyaranlar azaltıldı.

Değerlendirme: Hasta gece uyuduğunu ve kendisini daha iyi hissettiğini ifade etti.

- Hasta vücudunda monitör kablolarının olması nedeniyle rahat hareket edemediğini, kablolar dolayısı ile kendisine elektrik çarpmasından korktuğunu bildirdi.

Hemşirelik tanısı 6: Korku (NANDA Alanı 9: Başetme/Stres Toleransı, Sınıf 2: Başetme) $)^{[14]}$

Beklenen sonuç: Hastanın korkularının giderilerek rahatlamasının sağlanması

Hemşirelik girişimleri: Rahatça hareket edebileceği, hareketten dolayı herhangi bir şey olmayacağı, elektrik çarpması riskinin olmadığı anlatıldı. Elektrotların yerinden çıkmaması için hastaya file giydirildi. Böylece sağa sola daha rahat dönebileceği bildirildi.

Değerlendirme: Hasta yapılan girişimler sonucu daha rahat hareket ettiğini bildirdi.

- F. Ö'nün damar yolunun elinin üzerinde olmasının kendisini çok kısıtladığını ellerini rahatça yıkayamadığını ve rahat yemek yiyemediğini ifade etti.

Hemşirelik tanısı 7: Konforda bozulma (NANDA Alanı 12: Konfor, Sınıf 1: Fiziksel konfor) ${ }^{[14]}$

Beklenen sonuç: invazif girişimlerin günlük yaşam aktivitelerini etkilemeyecek şekilde uygulanarak hastanın rahatlamasının sağlanması.

Hemşirelik girişimleri: Damar yolu kontrol edildi. Deri üzerinde kızarıklık ve tespit bantlarının ıslak olduğu görüldü. Damar yolu çıkartılarak ön koldan damar yolu açıldı. Damar yolunun tespiti için antialerjik şeffaf tegaderm kullanıldı.

Değerlendirme: $F$. Ö. ellerini rahat kullanabildiğini ve rahatladığını ifade etti.

- Hastanın kalp ritmindeki ani değişimler, 65 yaş üzerinde ve obez olması, kan basıncını etkileyecek ilaçlar kullanması.

Hemşirelik tanısı 8: Düşme riski (NANDA Alanı 11: Güvenlik/Korunma, Sınıf 4: Çevresel tehlikeler) ${ }^{[14,15]}$
Beklenen sonuç: Hastanın düşmesinin önlenerek olası yaralanmalardan korunmasının sağlanması.

Hemşirelik girişimleri: Yatağın yüksekliği ayarlandı. Sık kullandığı eşyalar erişebileceği bir yere konumlandırıldı. Yatak kenarlıkları kaldırıldı. Yatak ayakları sabitlendi. Gece uyurken gece lambasının açık kalması gerektiği anlatıldı. Ortostatik hipotansiyonu önlemek için ayağa kalkarken birden bire kalkmaması gerektiği, kalkacağı zaman hemşire çağrı zili ile destek alabileceği belirtildi.

Değerlendirme: Hastada düşme meydana gelmedi. Ancak düşme riski devam etmektedir.

- Hastaya invazif girişimlerin yapılması ve hastane ortamında bulunması

Hemşirelik Tanısı 9: İnfeksiyon Riski (NANDA Alanı 11: Güvenlik/Korunma, Sınıf 1: Infeksiyon) $)^{[14]}$

Beklenen sonuç: Infeksiyonun önlenmesi

Hemşirelik girişimleri: Hastaya yapılan girişimlerde asepsi kurallarına uyuldu. Dengeli beslenmesi sağlandı. Uyku örüntüsü düzenlendi. İnfeksiyon belirtileri (ateş, lökosit, halsizlik v.b) takip edildi. Odasının düzenli olarak temizliği ve havalandırılması sağlandı. Hasta ve yakınlarına infeksiyonun önlenmesi ile ilgili bilgi verildi.

Değerlendirme: Hastada infeksiyon gelişmedi. Risk devam ediyor.

Konfor Kuramına Göre Sosyo-kültürel Olarak;

- F.Ö'nün obezitesinin (BKI: $38.8 \mathrm{~kg} / \mathrm{m}^{2}$ ) olduğu tespit edildi. Hasta kendisinin çiftçi olduğunu ekmeğini kendisinin yaptığını, sebze meyve yetiştirdiğini ve çok tükettiğini belirtmiştir. F. Ö'nün DM ve hipertansiyonu olduğu için kilo kontrolü oldukça önemlidir. Ayrıca hastanın varfarin sodyum içerikli ilaç kullanması nedeniyle sebze ve meyveleri önerildiği oranda kullanması ve beslenme alışkanlığını değiştirmesi gerekmektedir.

Hemşirelik tanısı 10: Risk eğilimli sağlık davranışı (NANDA Alanı 1: Sağlığın yükseltilmesi, Sınıf 2: Sağlığın yönetimi) ${ }^{[14]}$

Beklenen sonuç: Risk eğilimli sağlık davranışının önlenmesi ve diyetine uyum sağlayarak beslenmeyi sürdürmesi.

Hemşirelik girişimleri: Hasta doymadığını ifade ederek yakınlarından dışarıdan yiyecek istediği tespit edildi. Hasta ve yakınları ile görüşme yapılarak bu durum önlendi. Hastayla beslenme alışkanlığı hakkında görüşme yapıldı. Hastaya DM'si olduğu için az ekmek tüketmesi gerektiği, kullandığı bir ilaç nedeniyle yeşil yapraklı bitkileri ve meyveleri önerilen oranda tüketmesi gerektiği anlatıldı. Hastanın diyetisyenle görüşmesi sağlandı. Taburculuk sonrası düzenli aralıklarla diyetisyeni ziyaret etmesi önerildi. 
Değerlendirme: Hasta verilen bilgiler doğrultusunda önerilen diyete uyacağını bildirdi.

\section{Sonuç}

Kolcaba'nın "Konfor Kuramı" çerçevesinde olgunun bakım süreci; fiziksel, çevresel, sosyokültürel ve psikospiritüel boyutta ele alınarak problemlere yönelik hemşirelik tanıları belirlenmiş ve gerekli girişimler yapılarak holistik olarak konforu sağlanmıştır. Konfor kuramı, temeli bakım olan hemşirelik mesleğine farklı bir bakış açısı kazandırmıştır. Kuram ile AF olan bireylere sistematik olarak hemşirelik süreci uygulanabileceği, hemşirelik bakımının ana amaçlarından biri olan rahat ve konforun sağlanarak yaşam kalitesinin artırabileceği görülmüştür.

Hakem Değerlendirmesi: Dış bağımsız.

Çıkar Çatışması: Yazarlar arasında herhangi bir çıkar çatışması bulunmamaktadır.

Bilgilendirilmiş Onam: Olgu sunumunun yayınlanması için yazııı bilgilendirilmiş onam alındı.

Yazarlık Katkıları: Konsept: H.T.D., Y.Y., C..F., F.Ş.A.; Dizayn:Y.Y.; Veri Toplama veya İşleme: H.T.D.; Analiz veya Yorumlama: H.T.D., Y.Y., Ç.F., F.Ş.A.; Literatür Arama: H.T.D.; Yazan: H.T.D., Y.Y., Ç.F., F.Ş.A.

\section{Kaynaklar}

1. Kolcaba K, Fox C. Theeffects of guide dimagery on comfort of women with early- stage breast cancer going through radiation therapy. Oncology Nursing Forum 1999;26:67-71.

2. Kolcaba KY. A taxonomic structure for the concept comfort. Image J Nurs Sch 1991;23:237-240. [CrossRef]

3. Dowd T. Nursing theorists and their work. In: Tomey AM, Alligood MR, editors. KatharineKolcaba; Theory of Comfort. 7th ed. St Louis, Missouri: Mosby Elsevier; 2010. p. 657- 669.

4. Tutton E, Seers K. Comfort on a ward for older people. Journal of Advanced Nursing 2004;46:380-389. [CrossRef]

5. Kolcaba K, Kolcaba R. An analysis of comfort. J Adv Nurs 1991;16:1301-1310. [CrossRef]

6. Kolcaba K, Wilson L. Comfort care: a framework for perianesthesia nursing. J Perianesth Nurs 2002;17:102-113. [CrossRef]

7. Üstündağ H, Eti Aslan F. Koroner Arter Bypass Greft Cerrahisi Uygulanan Hastanın Bakımı ve Konforu. Yoğun Bakım Hemşireliği Dergisi 2011;15:22-28.

8. Karabacak Ü, Potur DC. Katherine Kolcaba: Comfort theory. In: Karadağ A, Çalışkan N, Baykara ZÇ, editors. Hemşirelik Teorileri ve Modelleri. 1st ed. İstanbul: Akademi Basın ve Yayıncılık; 2017. p .654-658.

9. Yücel ŞÇ. Kolcaba's comfort theory. Ege Üniversitesi Hemşirelik Yüksek Okulu Dergisi 2011;27:79-88.

10. Hawley MP. Nurse comfort ingstrategies: Perceptions of emergency department patient. Clinical Nursing Research 2000;9:441-459. [CrossRef]

11. Acar K, Aygın D. Orak Hücre Hastalığına Bağlı Akut Göğüs Sendromunun Konfor Kuramına Göre Değerlendirilmesi ve Hemşirelik Bakımı: Olgu sunumu. Online Türk Sağlık Bilimleri Dergisi 2016;1:36-43.

12. Karabacak Ü, Acaroğlu R. Theory of comfort. Maltepe Üniversitesi Hemşirelik Bilim ve Sanatı Dergisi 2011;4:197-202.

13. Kuğuoğlu S, Karabacak Ü. Genel konfor ölçeğinin Türkçe'ye uyarlanması. İstanbul Üniversitesi Florence Nightingale Hemşirelik Yüksekokulu Dergisi 2008;61:16-23.

14. Wilkinson MJ, Barcus L. PEARSON Hemşirelik Tanıları El Kitabı. In: Kapucu S, Akyar I, Korkmaz F, editors. 11nt ed. Ankara: Pelikan Yayınevi; 2018. p. 1081-1087.

15. Uysal H, Karataş C. Kronik Böbrek Yetersizliğinde Fonksiyonel Sağlık Örüntülerine Göre Hemşirelik Bakımı: Olgu Sunumu. Hacettepe Üniversitesi Hemşirelik Fakültesi Dergisi 2017;4(2):49-61. 